and severity of NEC were found to be significantly higher in premature infants born to preeclamptic mothers. Also, NEC developed significantly earlier in preeclamptic mother infants and duration of NEC was also found to be significantly longer in these infants.

\section{THE ROLE OF PERITONEAL DRAINAGE IN BELL'S STAGE 2 OF NECROTIZINF ENTEROCOLITIS}

doi:10.1136/archdischild-2012-302724.0283

${ }^{1} \mathrm{~N}$ Zampieri, ${ }^{1} \mathrm{G}$ Scirè, ${ }^{1} \mathrm{~A}$ Mantovani, ${ }^{1} \mathrm{~F}$ Laconi, ${ }^{2} \mathrm{~A}$ Pietrobelli, ${ }^{1} \mathrm{~F}$ Camoglio. ${ }^{1}$ Department of Anesthetic and Surgical Sciences, Pediatric Surgical Unit, University of Verona, Policlincio G.B.Rossi; ${ }^{2}$ Department of Pediatrics, Neonatal Intensive Care Unit, Policlinico G.B.Rossi, University of Verona, Verona, Italy

Introduction Necrotizing enterocolitis (NEC) has become the most common perinatal gastrointestinal emergency.

In literature there is an ongoing discussion on which surgical approach is the most efficient to maximise patients' survival: laparotomy or percutaneous drainage in case of intestinal perforation.

The aim of this study is to identify the preventive role of the peritoneal drain.

Materials and Methods Between September 2007 and September 2011 a prospective study was carried out at our Hospital.

Informed consent were obtained by parents before treatment;

Inclusion criteria were created.

Group A: placement of abdominal drainage in stage 2;

Group B: surgical treatment only with perforation.

Efficacy of early treatment (absence of subsequent intestinal perforation) was the primary end point; Survival at one month after drainage placement, Hospitalization, Mortality and Morbidity were considered for analysis.

Results 43 infants with stage II NEC were observed. At the end of the study the results shows that: 16 patients were treated with preventive peritoneal drain; 4 of these patients (25\%) underwent surgery for advanced NEC (intestinal perforation). Of the other 27 patients, 10 patients (37\%) developed advanced NEC, with intestinal perforation. $(p<0.05)$ in each group Patients with advanced NEC showed longer time of meconium evacuation if compared to the others (mean 5 vs. 2 days, $\mathrm{p}<0.05$ ).

Only $25 \%$ of patients treated with PPD underwent laparotomy for bowel perforation $(\mathrm{p}<0.05)$.

Conclusions The use of peritoneal drain in stage II NEC seems to be a safe alternative and treatment for these patients.

\section{OPIATE ADMINISTRATION TO PRETERM INFANTS - A RISK FACTOR FOR NECROTISING ENTEROCOLITIS?}

doi:10.1136/archdischild-2012-302724.0284

${ }^{1} \mathrm{M}$ Krishnamurthy, ${ }^{1} \mathrm{M}$ How, ${ }^{2} \mathrm{E}$ Wilson, ${ }^{2,3} \mathrm{~W}$ Cheng, ${ }^{1,3} \mathrm{~K}$ Tan. ${ }^{1}$ Monash Newborn, Monash Medical Centre, Mebourne; ${ }^{2}$ Paediatric Surgery, Monash Medical Centre, ${ }^{3}$ Department of Paediatrics, Monash University, Melbourne, VIC, Australia

Background and Aims Opiates like morphine and fentanyl are commonly used for sedation in the NICU. There are reports implicating early opiate exposure as a risk factor for NEC in preterm infants. We aimed to investigate if exposure to opiates in the first week of life was a risk factor for subsequent NEC in preterm infants in our NICU.

Methods Cases of NEC (Bell Stage $\geq 2$ ) in infants $<32$ weeks gestation age (GA) over a 3-year period (Jan 2008-Dec 2010) were identified from the NICU database. A case-control study was performed by pairing each infant with NEC to a random control, matched for year of birth, GA ( \pm 1 week) and birthweight (BW $\pm 20 \%$ ).

Total exposure to opiates (morphine and fentanyl) between days 1 and 7 was tabulated from medical records and the database. Twotailed Fisher's exact test was used to calculate the risk.
Results 27 infants with definite NEC were identified with mean GA $( \pm$ SD) of 27.2 $( \pm 2.1)$ weeks and BW of $998( \pm 348)$ g. 54 controls were matched with mean $( \pm$ SD) GA of $27.3( \pm 2.2)$ weeks and BW of $972( \pm 346) \mathrm{g}$. Exposure to opiates was not different between NEC and controls $(P=0.63$; Odds Ratio (95\% CI) of 0.73 (0.28-1.91). Median (range) daily opiate over the first week in NEC infants (morphine dose equivalent) was $14.3(0-259) \mu \mathrm{g} / \mathrm{kg} /$ day or approx. $0.6(0-11) \mu \mathrm{g} / \mathrm{kg} /$ hour.

Conclusions Early opiate exposure did not appear to be a significant risk factor for NEC in our population.

\section{CAN MEASUREMENT OF INTRAVESICAL PRESSURE BE USED FOR THE DIAGNOSIS AND FOLLOW UP OF NECROTIZING ENTEROCOLITIS?}

doi:10.1136/archdischild-2012-302724.0285

'S Tanriverdi, ${ }^{2} \mathrm{~A}$ Celik, ${ }^{1} \mathrm{O}$ Altun Koroglu, ${ }^{1} \mathrm{~F}$ Dulger, ${ }^{1} \mathrm{O}$ Uygur, ${ }^{1} \mathrm{M}$ Yalaz, ${ }^{1} \mathrm{M}$ Akisu, ${ }^{1} \mathrm{~N}$ Kultursay. 'Neonatology; ${ }^{2}$ Pediatric Surgery, Ege University Faculty of Medicine, Izmir, Turkey

Background and Aims Abdominal compartment syndrome refers to multiorgan failure secondary to increased intraabdominal pressure and circulatory failure. Early diagnosis and treatment of this clinical syndrome resulting with high mortality in children is possible via intravesical pressure (IVP)measurements. Data on IVP is limited in newborns with increased abdominal pressure due to diseases like necrotizing enterocolitis (NEC). We aimed to investigate the predictive value of consecutive IVP measurements for diagnosis and outcome of NEC.

Methods IVP was measured twice daily for 10 days in 61 premature infants below 1500 grams. Measurements of infants with and without NEC were compared.

Results Infants were grouped as;

Group 1: without NEC,

Group 2: NEC medically treated,

Group 3: operated for NEC.

Group 1 had lower IVP values compared to infants with NEC $(p=0.001)$. Group 2 and 3 had similiar IVP values $(p=0.155)$. A $10 \%$ increase in the consecutive IVP measurements was valuable for predicting NEC. Infants who died due to NEC had higher IVP values compared to surviving infants with NEC ( $p=0.043)$.

Conclusion IVP measurements may be helpful for the diagnosis of NEC. Mortality due to NEC in premature infants may also be predicted with high IVP values.

\section{LOW HAEMATOCRIT LEVELS IS COMMON IN PREMATURE INFANTS THAT DEVELOP NECROTISING ENTEROCOLITIS}

doi:10.1136/archdischild-2012-302724.0286

${ }^{1} \mathrm{~K}$ Povazai, ${ }^{2} \mathrm{~S}$ Bradley, ${ }^{1} \mathrm{G}$ Atreja, ${ }^{1} \mathrm{~A}$ Kapetanakis. 'Neonatal Medicine, Evelina Children's Hospital Guy's and St Thomas' Hospital NHS Foundation Trust, Kings Health Partners, ${ }^{2}$ Neonatology, St George's Hospital NHS Trust, London, UK

Introduction Necrotising enterocolitis (NEC) remains a serious complication of prematurity. NEC is associated with multiple factors. Recently concerns have been raised that transfusion related gut injury (TRAGI) may lead to NEC development.

Aim To identify if blood transfusion is implicated in the development of NEC in our population.

Methods Data collection from infants treated for definite NEC in two tertiary surgical neonatal units.

Results 49 infants developed NEC. GA: $\leq 24$ wks 16\%, 25-26 wks $16 \%, 27-29$ wks 37\%, 30-32 wks 19\%, 33-36 wks 12\%. Age of NEC: s7d: 7\%,d8-14: 19\%, >14d: 74\%. The lowest hematocrit (HCT) within 72 hours preceding NEC diagnosis was $<248 \%, 24-29$ in $28 \%$ of cases, $30-35$ in $36 \%, 36-42$ in $11 \%, 17 \%$ had Hct $>42$. $6 \%$ 